\title{
Risk of infection following a visit to the emergency department: a cohort study
}

\author{
Caroline Quach MD MSc, Margaret McArthur RN, Allison McGeer MD MSc, Lynne Li BSc, Andrew Simor MD, \\ Marc Dionne MD MPH, Edith Lévesque RN MSc, Lucie Tremblay RN MSc
}

Competing interests:

Caroline Quach has

received consultancy fees

from Novartis for studying

meningococcal group B

vaccine and has grant

support from Merck Frosst

for studying nosocomial

rotavirus infections and

from GlaxoSmithKline for

studying the effectiveness

of a monovalent rotavirus

vaccine in children.

Margaret McArthur

received salary from the

Canadian Patient Safety

Institute for coordinating

this study in Toronto.

Allison McGreer has

received consultancy fees

from Solvay Biologicals,

and has grant funding from

Response Biomedical,

Sanofi-Pasteur,

GlaxoSmithKline, Merck

Frosst, Novartis and

Hoffman-LaRoche. She has

received payment for

lectures from Sanofi-

Pasteur, GlaxoSmithKline,

Merck, Gilead Bioscience,

Hoffman-LaRoche and

Luminex. No competing

interests declared by Lynne

Li, Andrew Simor, Marc

Dionne, Edith Lévesque and

Lucie Tremblay.

This article has been peer reviewed.

Correspondence to:

Dr. Caroline Quach,

caroline.quach@mcgill.ca

CMAJ 2012. DOI:10.1503 /cmaj.110372

\section{ABSTRACT}

Background: The risk of infection following a visit to the emergency department is unknown. We explored this risk among elderly residents of long-term care facilities.

Methods: We compared the rates of new respiratory and gastrointestinal infections among elderly residents aged 65 years and older of 22 long-term care facilities. We used standardized surveillance definitions. For each resident who visited the emergency department during the study period, we randomly selected two residents who did not visit the emergency department and matched them by facility unit, age and sex. We calculated the rates and proportions of new infections, and we used conditional logistic regression to adjust for potential confounding variables.

Results: In total, we included 1269 residents of long-term care facilities, including 424 who visited the emergency department during the study. The baseline characteristics of residents who did or did not visit the emergency department were similar, except for underlying health status (visited the emergency depart-

๘ nfections associated with health care are an important health risk. A recent survey by the World Health Organization reported that $8.7 \%$ of patients in hospital developed such infections. ${ }^{1,2}$ The third leading cause of death in the United States is health care-associated deaths, with over 100000 people dying from infections associated with health care each year. ${ }^{3}$ In Canada, a point-prevalence survey found that $11.6 \%$ of adults in hospital experience a health care-associated infection. ${ }^{4}$

Little attention has been paid to infections acquired in other health care settings. Visiting an emergency department has been identified as a risk for disease during outbreaks of measles ${ }^{5,6}$ and SARS, ${ }^{7,8}$ but little is known about the potential risk of endemic infection from exposure in this setting. A visit to the emergency department differs from a stay in hospital: exposure and duration of contact with other patients is shorter, but ment: mean Charlson Comorbidity Index 6.1, standard deviation [SD] 2.5; did not visit the emergency department: mean Charlson Comorbidity index 5.5, SD 2.7; $p<0.001$ ) and the proportion who had visitors (visited the emergency department: $46.9 \%$; did not visit the emergency department: $39.2 \% ; p=0.01$ ). Overall, $21(5.0 \%)$ residents who visited the emergency department and $17(2.0 \%)$ who did not visit the emergency department acquired new infections. The incidence of new infections was 8.3/1000 patient-days among those who visited the emergency department and 3.4/1000 patient-days among those who did not visit the emergency department. The adjusted odds ratio for the risk of infection following a visit to the emergency department was 3.9 (95\% confidence interval 1.4-10.8).

Interpretation: A visit to the emergency department was associated with more than a threefold increased risk of acute infection among elderly people. Additional precautions should be considered for residents following a visit to the emergency department.

the number and density of patients with acute illness with whom there could be contact is higher.

Elderly residents of long-term care facilities are likely to be at the greatest risk of morbidity and mortality from communicable diseases acquired in the emergency department. When residents are transferred to the emergency department for assessment, they are likely to have longer stays and to be cared for in multibed observation areas and corridors. ${ }^{9}$ If they acquire an infection while in the emergency department, these residents may be the source of an outbreak upon return to their facility; this can lead to increases in workload and costs. A Canadian study estimated the cost of an influenza outbreak to be over $\$ 6000$ per 30 -day period, with an estimated incidence of death of $0.75 / 100$ residents during the same period. ${ }^{10}$ In this study, we explored the risk of acute respiratory and gastrointestinal infection associated with a visit to 
the emergency department among elderly residents of long-term care facilities.

\section{Methods}

\section{Study setting and design}

We included 22 residential long-term care facilities (3060 beds) for elderly people who require one to five hours of nursing care per day. These facilities had previously participated in infection control research, had the ability to provide census lists of residents and emergency department transfers, and were able to provide documentation of outbreaks. These facilities were located in the Greater Toronto Area, Ontario, Montréal, Quebec, and Rivière-du-Loup, Quebec. We enrolled residents aged 65 years and older who lived in the participating facilities between September 2006 and May 2008. We concentrated on nonsummer months (September-May) to maximize the likelihood of exposure to respiratory and gastrointestinal infections in the emergency department.

\section{Exposure and outcomes}

We included residents who visited an emergency department for reasons other than acute respiratory or gastrointestinal tract symptoms that did not result in admission to hospital (exposed). If a resident visited the emergency department more than once during a 10-day period, we included only the last visit.

Using census lists from each facility, we randomly selected two residents who did not visit the emergency department in the previous two weeks (unexposed). We selected the unexposed residents at the time of the exposed resident's return from the emergency department. We matched residents for the area or unit in the long-term care facility, age (within five years), sex and date of exposure. This ensured that all residents had the same likelihood of exposure to circulating viruses within the facility (e.g., sick health care worker or outbreak) and that all had the same likelihood of having a new infection detected (e.g., same type and intensity of charting).

To minimize uncertainty about the diagnosis of acute infection, we excluded immunocompromised residents (after organ transplant, receiving chemotherapy and dialysis or taking immunosuppressive medication) and those with a chronic fever.

Our primary outcome was the development of symptoms consistent with a new acute respiratory or gastrointestinal tract infection two to seven days after return from an emergency department. We used standardized surveillance definitions for respiratory and gastrointestinal infections in longterm care facilities (Box 1); these definitions have previously been validated and published..$^{11,12}$

Trained staff performed blinded assessment of the outcomes by reviewing photocopies of charts, including notes, written orders and the results of ordered tests. Staff also confirmed eligibility and obtained demographic and medical information (e.g., age, underlying illnesses, Charlson Comorbidity Index score, allergies, smoking status and vaccination history).

During the study period, infection control practitioners in each facility kept copies of outbreak records for the study. We used these data to determine if an outbreak was ongoing at the time the resident visited the emergency department. We defined an outbreak as the presence of two or more cases of influenza-like illness or gastroenteritis linked epidemiologically within a 10-day period. ${ }^{13,14}$

Our study was approved by the research ethics board at McGill University and the administration, medical advisory council and residents' council or equivalent body in each long-term care facility.

\section{Statistical analysis}

Based on US surveillance data from long-term care facilities where the annual mean rate for respiratory and gastrointestinal infections is 1.95 infections/1000 resident-days, ${ }^{15}$ we expected that $1.5 \%$ of residents who did not visit the emergency department would acquire a new infection during any six-day period during the winter months. We chose a sample size of 405 residents who visited and 810 residents who did not visit the emergency department to provide $80 \%$ power (two-sided $\alpha=0.05$ ) to detect an absolute difference in the risk of infection of $3 \%$.

We compared the baseline characteristics of the residents using Student $t$ test for continuous variables and $\chi^{2}$ and Fisher exact tests for dichotomous variables. We calculated the incidence of new infections as a proportion, and we calculated the crude relative risk (RR) associated with a visit to the emergency department. We used multivariable analyses to adjust for confounding variables and to identify effect modifiers. The variables of interest were smoking, contact with other health care settings, other potential infectious contacts, Charlson Comorbidity Index score, ${ }^{16}$ the Katz Index of Independence in Activities of Daily Living ${ }^{17}$ and influenza vaccination status.

We also analyzed data from the matched cohort using a backward, stepwise conditional logistic regression model. We kept variables in the final model if their coefficient was statisti- 
cally significant, if they confounded variables already in the model or if they significantly improved the model fit. The following variables were forced in the model to adjust for baseline imbalances between the exposed and unexposed groups: the presence of visitors, asthma and cardiac disease. The most parsimonious model was kept based on the Akaike information criterion. We considered all $p$ values to be significant at 0.05 , and they were two-sided.

\section{Results}

During the study period, 424 residents visited the emergency department for reasons other than possible gastrointestinal or respiratory infection and were not admitted to hospital. We matched these residents to 845 residents without visits to the emergency department. The baseline characteristics of both groups were similar (Table 1), except that, compared to those who did not visit the emergency department, more residents who visited the emergency department dined in their own room $(8.3 \%$ v. $3.1 \% ; p<0.001)$ and had visitors during the study period (46.9\% v. $39.2 \%$; $p=0.01)$. Those who visited the emergency department had higher average scores on the
Charlson Comorbidity Index than those who did not visit the emergency department (6.1 v. $5.5 ; p$ $<0.001)$. The residents' underlying medical conditions are summarized in Table 1.

Residents who did not visit the emergency department were more likely than those who visited the emergency department to be more independent (Katz Index categories A and B; Table 1). There were no other differences on the Katz Index between groups. During the study period, the facilities declared 12 outbreaks of respiratory illness (influenza $=2$, respiratory syncytial virus $=2$, other respiratory viruses $=8$ ) and 9 outbreaks of acute gastroenteritis (caliciviruses $=1$, no virus identified $=8$ ).

The reasons for residents' visits to the emergency department and the proportion of subsequently infected residents are summarized in Table 2. Impaired mobility (including falls and fractures), neurologic and noninfectious gastrointestinal problems, and skin, soft tissue and cardiovascular complaints accounted for over $70 \%$ of visits. Overall, $10 \%$ of residents with a cardiovascular complaint and $11 \%$ of those with a urinary tract infection developed an infection following their visit to the emergency department.

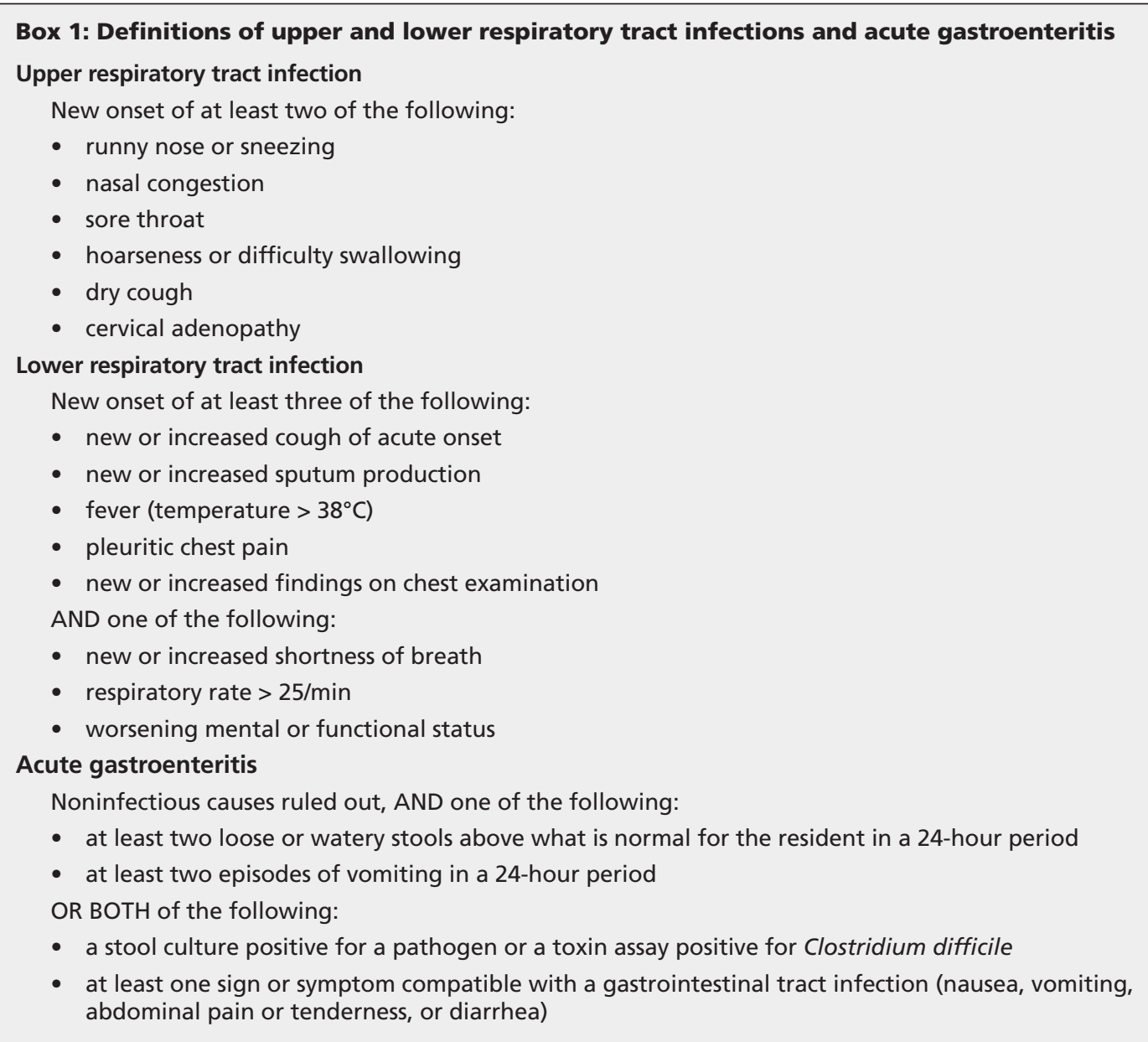


Table 1: Baseline characteristics of patients who did and did not visit the emergency department during the study period

No. (\%) of patients*

\begin{tabular}{|c|c|c|c|}
\hline \multirow[b]{2}{*}{ Characteristics } & \multicolumn{2}{|c|}{ No. $(\%)$ of patients* } & \multirow[b]{2}{*}{$p$ value } \\
\hline & $\begin{array}{c}\text { No visit to the } \\
\text { emergency department } \\
n=845\end{array}$ & $\begin{array}{l}\text { Visited the emergency } \\
\text { department } \\
n=424\end{array}$ & \\
\hline Age, yr, mean (SD) & $85.8(6.0)$ & $85.2(10.7)$ & $\dagger$ \\
\hline Age range, yr & $69.6-104.9$ & $65.5-105.2$ & \\
\hline Male & $268 \quad(31.7)$ & $147 \quad(34.7)$ & $t$ \\
\hline Dining room on unit & $681 \quad(81.5)$ & $322 \quad(79.3)$ & 0.06 \\
\hline Dined in room & (3.1) & $(8.3)$ & $<0.001$ \\
\hline Had roommate(s) & $384 \quad(45.4)$ & $(44.3)$ & 0.7 \\
\hline No. of roommates, mean (SD) & $1.10(2.1)$ & $1.1(2.3)$ & \\
\hline III roommate & $61 \quad(7.2)$ & $27 \quad(6.4)$ & 0.6 \\
\hline Roommate with a respiratory infection & $(3.0)$ & (3.3) & 0.8 \\
\hline Smoker & $(4.0)$ & $(5.2)$ & 0.3 \\
\hline Influenza vaccine received $\ddagger$ & $576 \quad(68.2)$ & $280 \quad(66.0)$ & 0.4 \\
\hline Pneumococcal vaccine received§ & $507 \quad(60.0)$ & $(59.9)$ & 0.97 \\
\hline Had visitors & $331 \quad(39.2)$ & $199 \quad(46.9)$ & 0.01 \\
\hline \multicolumn{4}{|l|}{ Katz Index } \\
\hline A: independent & $(4.9)$ & $(2.2)$ & 0.02 \\
\hline $\begin{array}{l}\text { B: independent in all but one } \\
\text { function }\end{array}$ & $68 \quad(8.3)$ & $(4.8)$ & 0.02 \\
\hline C: Katz B + dependent in bathing & $(6.8)$ & $(8.1)$ & 0.4 \\
\hline D: Katz C + dependent in dressing & $44 \quad(5.3)$ & $(7.4)$ & 0.2 \\
\hline $\begin{array}{l}\text { E: Katz D + dependent in going } \\
\text { to toilet }\end{array}$ & $106 \quad(12.9)$ & $72 \quad(17.2)$ & 0.04 \\
\hline $\begin{array}{l}\mathrm{F}: \text { Katz } \mathrm{E}+\text { dependent in } \\
\text { transferring }\end{array}$ & $229 \quad(27.8)$ & $95 \quad(22.7)$ & 0.05 \\
\hline G: dependent & $280 \quad(34.0)$ & $156 \quad(37.2)$ & 0.3 \\
\hline $\begin{array}{l}\text { O: dependent in two or more } \\
\text { functions but not classifiable as C, } \\
D, E \text { or F }\end{array}$ & $1 \quad(0.1)$ & $(0.5)$ & 0.3 \\
\hline $\begin{array}{l}\text { Charlson Comorbidity Index score, } \\
\text { mean (SD) }\end{array}$ & $5.5(2.7)$ & $6.1(2.5)$ & $<0.001$ \\
\hline Underlying medical condition & $n=704$ & $n=360$ & \\
\hline Neurologic disorders (overall) & $556 \quad(79.0)$ & $265 \quad(73.6)$ & 0.05 \\
\hline Parkinson & $49 \quad(7.0)$ & $(5.0)$ & 0.2 \\
\hline Seizures & $(4.8)$ & $(5.0)$ & 0.9 \\
\hline Previous cerebrovascular accident & $97 \quad(13.8)$ & $(17.0)$ & 0.2 \\
\hline Cardiovascular disease (overall) & $224 \quad(31.8)$ & $140 \quad(39.0)$ & 0.02 \\
\hline Previous myocardial infarction & $55 \quad(7.8)$ & $(7.5)$ & 0.9 \\
\hline Coronary artery disease & $116 \quad(16.5)$ & $76 \quad(21.1)$ & 0.06 \\
\hline Congestive heart failure & $80 \quad(11.4)$ & $65 \quad(18.1)$ & 0.003 \\
\hline Pulmonary disease (overall) & $95 \quad(13.5)$ & $(16.1)$ & 0.3 \\
\hline Asthma & $25 \quad(3.6)$ & $(6.4)$ & 0.04 \\
\hline $\begin{array}{l}\text { Chronic obstructive pulmonary } \\
\text { disease }\end{array}$ & $74 \quad(10.5)$ & $43 \quad(11.9)$ & 0.5 \\
\hline Diabetes & $158 \quad(22.4)$ & $100 \quad(27.8)$ & 0.06 \\
\hline $\begin{array}{l}\text { Note: SD = standard deviation } \\
\text { *Unless stated otherwise. } \\
\text { †Matching variables. } \\
\text { ‡Residents who had a record of influenza vaccin } \\
\text { §Residents who had a record of prior pneumoco }\end{array}$ & $\begin{array}{l}\text { nation for the current season. } \\
\text { occal vaccination. }\end{array}$ & & \\
\hline
\end{tabular}


In our univariable unmatched analysis (Table 3 ), there was a 2.5 -fold increase in the risk of infection associated with a visit to the emergency department (RR 2.5, 95\% confidence interval [CI] 1.3-4.6). This translates to an absolute risk difference of $3.0 \%$. This increase in risk was similar for gastroenteritis and respiratory tract infections. The incidence of infection was 8.3/1000 resident-days among those who visited the emergency department and 3.4/1000 resident-days among those with no visit $(p=0.007)$. During any six-day period during the study period, $1.4 \%$ of residents had an acute respiratory infection, equivalent to a rate of 6.6 infections $/ 100$ resident-months.

In the univariable matched analysis (Figure 1), a visit to the emergency department was associated with a 2.6-fold increase in the risk of infection (odds ratio [OR] 2.63; 95\% CI 1.355.13). After stratification for the presence of an outbreak, a visit to the emergency department was associated with increased risk of infection only in the absence of an outbreak in the facility at that time (OR 3.9 [95\% CI 1.7-8.6] v. OR 0.5 [95\% CI 0.1-2.8] if an outbreak was present). In the multivariable conditional logistic regression models (Figure 1), the adjusted OR for infection associated with a visit to the emergency department was 3.86 (95\% CI 1.38-10.77).

\section{Interpretation}

In our study, a visit to the emergency department between September and May was associated with increased risk of a new respiratory or gastrointestinal infection in the week following the visit, but only in the absence of an outbreak at the resident's facility. In the presence of an ongoing outbreak, residents who visited the emer-

Table 2: Reasons for visits to the emergency department and the proportion of residents who subsequently developed an infection

\begin{tabular}{|lccc|}
\hline Reason for visit & $\begin{array}{c}\text { No. of } \\
\text { residents }\end{array}$ & $\begin{array}{c}\text { Developed an infection, } \\
\text { no. (\%) }\end{array}$ \\
\hline Mobility impairment & 75 & 5 & $(6.7)$ \\
\hline Neurologic issue & 51 & 1 & $(2.0)$ \\
\hline Gastrointestinal issue (noninfectious) & 46 & 2 & $(4.4)$ \\
\hline Skin and soft tissue & 30 & 1 & $(3.3)$ \\
\hline Cardiovascular & 29 & 3 & $(10.3)$ \\
\hline Urinary tract infection & 18 & 2 & $(11.1)$ \\
\hline Renal & 5 & 0 & $(0)$ \\
\hline Psychiatric & 2 & 0 & $(0)$ \\
\hline Other & 70 & 2 & $(2.9)$ \\
\hline Data missing & 98 & 5 & $(5.1)$ \\
\hline
\end{tabular}

*The proportion of patients who developed an infection did not differ significantly according to the reason for the emergency department visit ( $p=0.65$ by the $\chi^{2}$ test) gency department did not have an increased risk of infection.

Residents who visited the emergency department had higher scores on the Charlson Comorbidity Index (because of asthma and cardiac disease) and, compared to those who did not visit the emergency department, they were more likely to dine in their own room and have visitors. Because in-room dining should decrease the risk of acquiring infection because of reduced exposure to other residents and staff, this difference would be expected to reduce the strength of the association. The increased number of visitors, however, might be expected to increase the risk of acquiring an infection, thereby inflating the risk associated with a visit to the emergency department. Therefore, we adjusted our final result for the presence of visitors despite the fact that this variable did not appear to be independently associated with a risk of infection. We also adjusted for asthma and cardiac disease, because there was an imbalance in the baseline characteristics between groups. However, although it is not unexpected that residents with more comorbid conditions would be more likely to visit the emergency department than patients with less comorbid conditions, we would not expect that those with more severe or complicated illness would be at different risk of acute respiratory or gastrointestinal illness.

Other studies of the risk of respiratory or gastrointestinal infections in ambulatory care involve pediatric populations. Two studies reported an increased risk of measles ${ }^{4.5}$ in children exposed in emergency departments during community outbreaks. However, measles is transmitted by the airborne route and differs from respiratory and gastrointestinal infections (droplet and contact transmission). One study in a pediatric population reported a nonstatistically significant decrease in the risk of acute respiratory or gastrointestinal illness after a visit to the emergency department ( $15.3 \%$ among those who visited the emergency department v. $23.4 \%$ among those with no visit). ${ }^{18}$ Visits to pediatric offices were not associated with an increased risk of acute respiratory or gastrointestinal illness. ${ }^{19}$ The absence of a detectable increase in risk in pediatric offices $(30 \%$ among those who visited a pediatric office v. $32 \%$ among those with no visit) may be explained by the preponderance of well visits or by shorter wait times compared with emergency department settings. The absence of increased risk among children who visit pediatric emergency departments may be because of different practices in pediatric emergency departments, shorter lengths of stay, or greater exposure of children in community settings. 
In contrast, residents of long-term care facilities often have multiple chronic diseases and functional impairments that predispose them to infection. Shared sources of air, food, water and medical care facilitate both the introduction and transmission of infectious agents among residents. Prolonged length of stay, limited capacities for diagnosis and variable infection control programs may allow outbreaks to propagate and persist for many months, underlining the importance of identifying potential sources of infectious agents. ${ }^{20}$ In our study, the overall rate of respiratory infections was 2.4/1000 residentdays, which is higher than the rates reported for influenza-like illness in a community sample of adults aged 65 years and older during an influenza pandemic in the United States (1.1 infections/1000 person-days). ${ }^{21}$

Table 3: Univariable, unmatched analysis* of the risk of infection associated with a visit to the emergency department

\begin{tabular}{|c|c|c|c|c|}
\hline \multirow[b]{2}{*}{ Outcome } & \multicolumn{2}{|c|}{ No. (\%) of residentst } & \multirow[b]{2}{*}{$\begin{array}{l}\text { Relative risk } \\
(95 \% \mathrm{Cl})\end{array}$} & \multirow[b]{2}{*}{$p$ value } \\
\hline & $\begin{array}{c}\text { No visit to the } \\
\text { emergency department } \\
n=845\end{array}$ & $\begin{array}{l}\text { Visited the emergency } \\
\text { department } \\
n=424\end{array}$ & & \\
\hline Any infection & $17(2.0)$ & $21(5.0)$ & $2.5(1.3-4.6)$ & 0.004 \\
\hline $\begin{array}{l}\text { Any infection per } 1000 \\
\text { patient-days }\end{array}$ & 3.4 & 8.3 & & 0.007 \\
\hline Respiratory tract infection & $8(1.0)$ & $10(2.4)$ & $2.5(1.0-6.3)$ & 0.04 \\
\hline Gastroenteritis & $9(1.1)$ & $11(2.6)$ & $2.4(1.0-5.8)$ & 0.04 \\
\hline
\end{tabular}

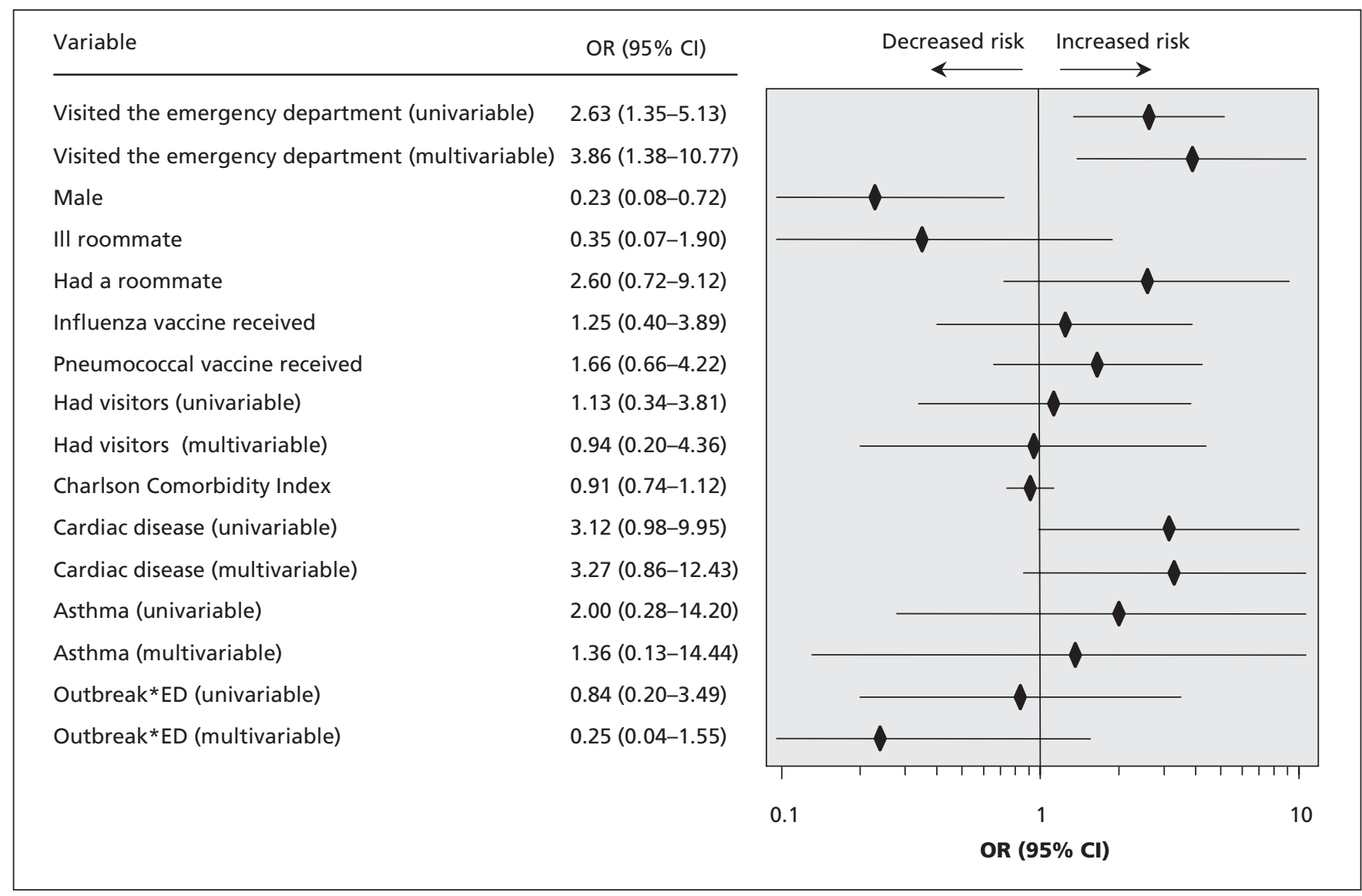

Figure 1: Matched, univariable and multivariable analysis* of the risk of infection after a visit to the emergency department. Note: $\mathrm{Cl}=$ confidence interval, $\mathrm{ED}=$ emergency department, $\mathrm{OR}=$ odds ratio. *Determined by conditional logistic regression. 
Outbreaks of respiratory tract infections are common and likely underestimated in long-term care facilities. A Canadian study reported 46 outbreaks, most of which (42\%) were due to respiratory viruses, over a three-year period in five nursing homes. ${ }^{22}$ These outbreaks occurred mainly during the winter months, and fewer than $50 \%$ were identified prospectively as outbreaks. ${ }^{22}$ Prospective monitoring of gastroenteritis outbreaks in hospitals and nursing homes in England identified that 33 of 271 outbreaks (12\%) occurred in long-term care facilities. ${ }^{23}$

\section{Limitations}

Staff in long-term care facilities generally understand the importance of identifying acute respiratory and gastrointestinal infections and have surveillance programs for outbreaks. However, such surveillance programs are underfunded, and chart reviews usually identify more infections than are detected through surveillance. ${ }^{24}$ In our study, there could be potential detection bias if the exposed residents were monitored more closely or if their symptoms were documented with more precision. Because we did not consider visits to the emergency department to be a risk factor for the development of new infections at the time of the study, we do not believe that such a bias would be important.

This study has the limitations of a retrospective chart review. It is possible that some infectious outcomes were missed. However, the use of standardized and validated definitions for the diagnosis of respiratory and gastrointestinal infections,,${ }^{7.8}$ the matching of exposed and unexposed residents within the same unit, and the blinding of reviewers to the exposure status should have balanced this risk in the two groups. Precise data from the various emergency departments were not available. Although we would have liked to correlate the risk of infection with time spent in the emergency department, the data were too incomplete to allow us to do so. Microbiological diagnosis of infectious outcomes would be ideal, but is rarely performed and was not feasible in this study. Although we included multiple facilities and emergency departments, they were all from one country and studied during only two seasons. Thus, our results may not be generalizable to other populations, all years or other types of health care systems.

\section{Conclusions}

A visit to the emergency department was associated with a more than threefold increased risk of acute respiratory or gastrointestinal infection. Confirmation of these results with studies of specific types of infection with laboratory testing is required. Further research is also required to identify specific sources of transmission in the emergency department (e.g., waiting room, examination and observation rooms, corridor, staff or other patients) and to monitor for the presence and compliance to infection control guidelines and policies. Once systemic reasons for the transmission of infection in emergency departments are understood, interventions to reduce the risk should be studied. In the meantime, considerations should be given to the implementation of additional precautions for residents for five to seven days after their return from the emergency department.

\section{References}

1. Ducel G, Fabry J, Nicolle L, editors. Prevention of hospitalacquired infections: a practical guide. 2nd ed. Geneva (Switzerland): World Health Organization. Department of communicable disease, surveillance and response; 2002.

2. Mayon-White RT, Ducel G, Kereselidze T, et al. An international survey of the prevalence of hospital-acquired infections. J Hosp Infect 1988;11(Suppl A):43-8.

3. Millar J. System performance is the real problem. Health Pap 2001;2:79-84

4. Gravel D, Taylor G, Ofner M., et al. Point prevalence survey for healthcare-associated infections within Canadian adult-care hospitals. J Hosp Infect 2007;66:243-8.

5. Miranda AC, Falcão J, Dias JA, et al. Measles transmission in health facilities during outbreaks. Int J Epidemiol 1994;23:843-8.

6. Farizo KM, Stehr-Green PA, Simpson DM, et al. Pediatric emergency room visits: a risk factor for acquiring measles. Pediatrics 1991;87:74-9.

7. Poutanen SM, Low DE, Henry B, et al.; National Microbiology Laboratory, Canada; Canadian Severe Acute Respiratory Syndrome Study Team. Identification of Severe Acute Respiratory Syndrome in Canada. N Engl J Med 2003;348:1995-2005.

8. Chen YC, Huang LM, Chan CC, et al. SARS in hospital emergency room. Emerg Infect Dis 2004;10:782-8.

9. Yim VW, Graham CA, Rainer TH. A comparison of emergency department utilization by elderly and younger adult patients presenting to three hospitals in Hong Kong. Int J Emerg Med 2009; 2:19-24.

10. Risebrough NA, Bowles SK, Simor AE, et al. Economic evaluation of oseltamivir phosphate for postexposure prophylaxis of influenza in long-term care facilities. J Am Geriatr Soc 2005; 53:444-51.

11. McGeer A, Campbell B, Emori G, et al. Definitions of infection for surveillance in long-term care facilities. Am J Infect Control 1991;19:1-7.

12. Loeb M, McGeer A, McArthur M, et al. Surveillance for outbreaks of respiratory tract infections in nursing homes. CMAJ 2000;162:1133-7.

13. Guide d'intervention influenza en milieu d'hébergement et de soins de longue durée : prévention, surveillance et contrôle. Québec (QC): Santé et des services sociaux du Québec; 2006.

14. Comité sur les infections nosocomiales du Québec (CINQ). Mesures de contrôle et prévention des éclosions de cas de gastro-entérite infectieuse d'allure virale (norovirus) à l'intention des établissements de soins. Québec (QC): Institut national de santé publique du Québec; 2005.

15. Stevenson KB, Moore J, Colwell H, et al. Standardized infection surveillance in long-term care: Interfacility comparisons from a regional cohort of facilities. Infect Control Hosp Epidemiol 2005;26:231-8

16. Charlson ME, Pompei P, Ales KL, et al. A New method of classifying prognostic comorbidity in longitudinal studies: development and validation. J Chronic Dis 1987;40:373-83.

17. Katz S. Assessing self-maintenance. Activities of daily-living mobility and instrumental activities of daily-living. J Am Geriatr Soc 1983;31:721-7.

18. Quach C, Moore DL, Ducharme F, et al. Do pediatric emergency departments pose a risk of infection? BMC Pediatr 2011;11:2.

19. Lobovits AM, Freeman J, Goldmann AD, et al. Risk of illness after exposure to a pediatric office. N Engl J Med 1985;313:425-8.

20. Strausbaugh LJ, Sukumar SR, Joseph CL. Infectious disease 
outbreak in nursing homes: an unappreciated hazard for frail elderly persons. Clin Infect Dis 2003;36:870-6.

21. Self-reported influenza-like illness during the $2009 \mathrm{H} 1 \mathrm{~N}$ influenza pandemic - United States, September 2009-March 2010. MMWR Morb Mortal Wkly Rep 2011;60:37-41.

22. Falsey AR, Treanor JJ, Betts RF, et al. Viral respiratory infection in the institutionalized elderly: clinical and epidemiological findings. J Am Geriatr Soc 1992;40:115-9.

23. Lopman BA, Reacher MH, Vipond IB, et al. Clinical manifestation of norovirus gastroenteritis in health care settings. Clin Infect Dis 2004;39:318-24.

24. Do MT, Ratnasingham S. Public Health and Epidemiology Report Ontario: Review of reported respiratory infections outbreaks in institutions in Ontario 2001-2003. Toronto (ON): Ministry of Health and Long-Term Care; 2004. Available: www.health. gov.on.ca/english/providers/pub/phero/pdf/2004/phero_0504.pdf (accessed 2011 Mar. 1).

Affiliations: From the Division of Infectious Disease, Department of Pediatrics and Medical Microbiology (Quach, Li), The Montreal Children's Hospital, McGill University, Montréal, Que.; Institut national de santé publique du Québec (Quach, Dionne), Québec, Que.; the Department of Microbiology (McArthur, McGeer), Mount Sinai Hospital, University of Toronto; the Department of Microbiology (Simor), Sunnybrook Health Sciences Center, University of Toronto, Toronto, Ont.; the Department of Microbiology
(Levesque), Centre de santé et de services sociaux de Rivière-du-Loup, Riviére-du-Loup, Que.; and the Maimonides Geriatric Center (Tremblay), Montréal, Que.

Contributors: Caroline Quach designed the study protocol, supervised the data collection in Montreal, analyzed the data, and wrote the manuscript. Margaret McArthur supervised the data collection in Toronto. Allison McGeer participated in the design of the protocol. Lynne Li performed additional data analysis. Edith Levesque supervised the data collection in Rivière-du-Loup. Andrew Simor, Marc Dionne, Lucie Tremblay critically reviewed the protocol. All of the authors reviewed the manuscript and approved the final version submitted for publication.

Funding: This work was supported by the Canadian Patient Safety Institute (grant no. RFA06-1051-QC), the Quebec Ministry of Health and the Canadian Institutes for Health Research (grant no. 83022). The study sponsors had no role in the design of the study, the collection, analysis, or interpretation of data, the writing of the report or the decision to submit the article for publication.

Acknowledgements: The authors thank the students who participated in the data collection and the research coordinators on both sites (Deirdre McCormack and Brenda Coleman). 